\title{
The influence of three different load carrying methods on gait parameters of Indian construction workers
}

\begin{abstract}
Many examinations of various load configurations on healthy men of other professions like military services have been made, but not much on men engaged in manual labour work in construction industries. Construction workers were found to have higher prevalence of lower extremity problems when carrying heavy load during daily activities at the construction sites. The purpose of this study was to examine the changes in gait patterns of Indian construction workers while carrying a $30 \mathrm{Kg}$ load on their head, on the hand, and across one shoulder. Twenty healthy daily wage male workers without existing clinical orthopaedic problems were selected for this study, ranging in ages from 21 to 40years. Thirty six reflective markers were placed on the subjects' lower limb. Six Qualisys Motion Capture Oqus cameras were used to film the subjects, walking along a 75 meter walkway. Each worker was asked to walk at his self-selected speed without any load to establish a baseline and then, in random order, walked with a 30 kilograms load on the head, on the hand, and diagonally across one shoulder. The influence of load carrying methods on different gait parameters like speed, stride length, stride width, step time, stance time, swing time, cadence, cycle time, double limb support and etc. were observed. Workers $(n=20)$ walked with significantly different gait parameters when walking with three different load carrying configurations compared with the baseline at $\mathrm{p}<0.05$. Carrying a heavy load on head appeared to cause the least deviation from normal gait pattern among the Indian manual construction workers.
\end{abstract}

Volume 3 Issue 4 - 2017

\author{
Arundhati Guha Thakurta,' Rauf Iqbal,' \\ Amitabha $\mathrm{De}^{2}$ \\ 'Ergonomics and Human Factors and Engineering, National \\ Institute of Industrial Engineering (NITIE), India \\ ${ }^{2}$ Rajiv Gandhi Indian Institute of Management (IIM), India
}

Correspondence: Arundhati Guha Thakurta, National Institute of Industrial Engineering(NITIE), Ergonomics and Human Factors and Engineering, OCA Building, Third floor, Vihar Lake Road, Mumbai-400087, Maharashtra, India, Tel +919819891906, Email arundhatil8@gmail.com

Received: January 23, 2017| Published: April 06, 2017

Keywords: gait, load, construction, workers

\section{Introduction}

Observations showed a variety of ergonomic issues emerged among the Indian construction workers who were engaged in handling heavy materials manually. Issues like lack of space, poor working plan, awkward postures, carrying heavy loads and etc. were identified as ergonomic risk factors causing health hindrance to do daily activities but the commercial pressures on the labours, being the most dynamic element leading them to take risks compromising their safety. Improving ergonomic performance of the workers has become a goal for the construction industries in India as it may also contribute to hamper significantly the productivity of the workers as reported in many previous studies. ${ }^{1}$ Musculoskeletal problems were found to be the commonest and most prevalent health issues affecting almost $77 \%$ of the Indian construction workers. ${ }^{2}$ Construction labours in daily work were found to have a higher incidence of musculoskeletal injuries when carrying a heavy load during their daily work. ${ }^{3}$ Workers were found working without protective devices even though provided, mostly favouring barefooted walk being unaware of its degenerative effects. Compared with different musculoskeletal issues due to work activity, construction workers engaged in daily load carriage activity were more prone to lower limb injuries.

The continuous process of bending, and squatting to lift the heavy load and prolonged walking over the undulated surfaces involving stairs climbing as well contributed to the high rate of lower limb musculoskeletal injuries among Indian construction workers engaged in manual handling of loads. Appropriate leg and trunk muscle strength appeared to be critical for Indian workers to function on jobs that required carrying loads and walking. Workers with limited leg extensor muscle strength appeared to have a higher incidence of musculoskeletal injuries than workers with strong leg extensor muscle. ${ }^{4}$ Previous studies reported that poor design of workplace and tools used by them contributed to high rate of musculoskeletal injuries during their work. ${ }^{5}$ Various load configurations for healthy men had been examined, but considering the labour intensive industrial sectors like construction industries in India, much less investigations were done. The purposes of this study was to examine the changes in gait patterns of Indian construction workers while carrying a $30 \mathrm{Kg}$ load on the head, diagonally across one shoulder and on the hand.

\section{Materials and methods}

Twenty healthy male construction workers from Mumbai suburb area without any past history of orthopaedic surgery were selected for this study. All the workers involved in load carriage task on a regular basis for more than five years of experience. Their ages ranged from 21 to 40years. Written consent were obtained and then a screening examination was conducted to ensure each worker was free of clinical orthopaedic problems in the spine and legs. Thirty six reflective markers were placed on each worker's legs and pelvis in total. The worker's lower body, starting from the pelvis to foot, was provided with the markers. The specified markers, which validated the Visual 3D to reassemble the digital skeleton of each worker, included the following: Pelvis defined by the markers placed on right and left anterior and posterior superior iliac spine. Hip was defined 
by markers on distal endpoints at the left and right greater trochanter. The markers placed on proximal endpoints for thighs were the distal pelvis endpoints and the distal endpoints for thighs were the lateral and medial epicondyle on left and right legs. The proximal endpoints markers for the shank were the thigh's distal end points and the distal endpoints for the shank were the lateral and medial malleolus on left and right legs. One heel marker for each left and right legs was placed on the posterior side of the calcaneus. Two markers were placed on the first and fifth metatarsal bone to define foot of each legs. Markers tracked by the cameras for both static and dynamic trials.

An array of six high speed cameras (type: 'Oqus') by the company
'Qualisys' were used to film each worker walking along a 75meter walk way having two Kistler, Switzerland force plates were used. Each worker first walked along the walkway at his self-selected speed without any load to establish a baseline and then, in random order, walked along the walkway with a $30 \mathrm{~kg}$ load on the head, across one shoulder and on hand (frontal plane). Each worker followed the same protocol for the four testing conditions. The workers were allowed to walk on both the force plate- 1 and force plate- 2 and were stepped by left foot and right foot respectively. They were asked to walk for one hour (sixty minutes) during which five trials were recorded by the Oqus camera infrared digital cameras. The best three trials were considered for analysis (Figure 1).

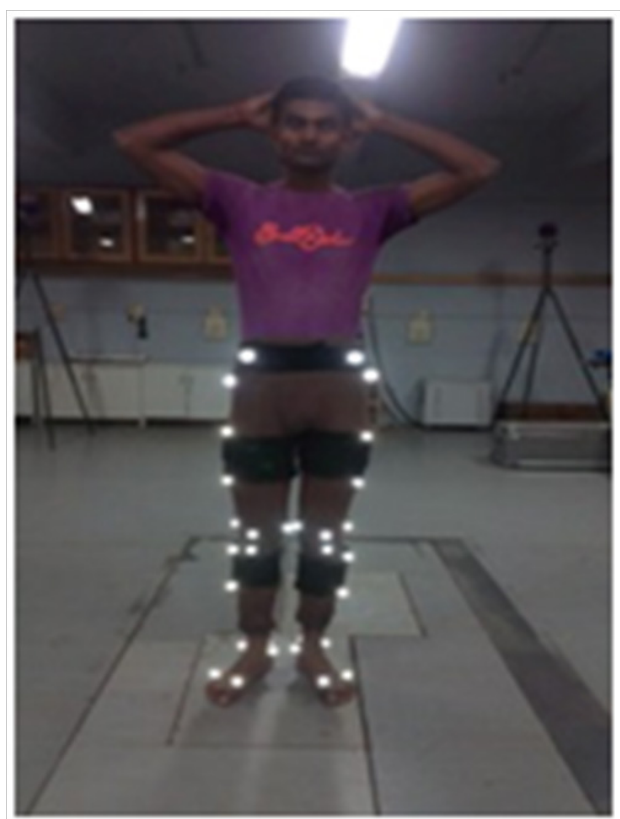

Figure A Standing Mode (Subject's age-22years).

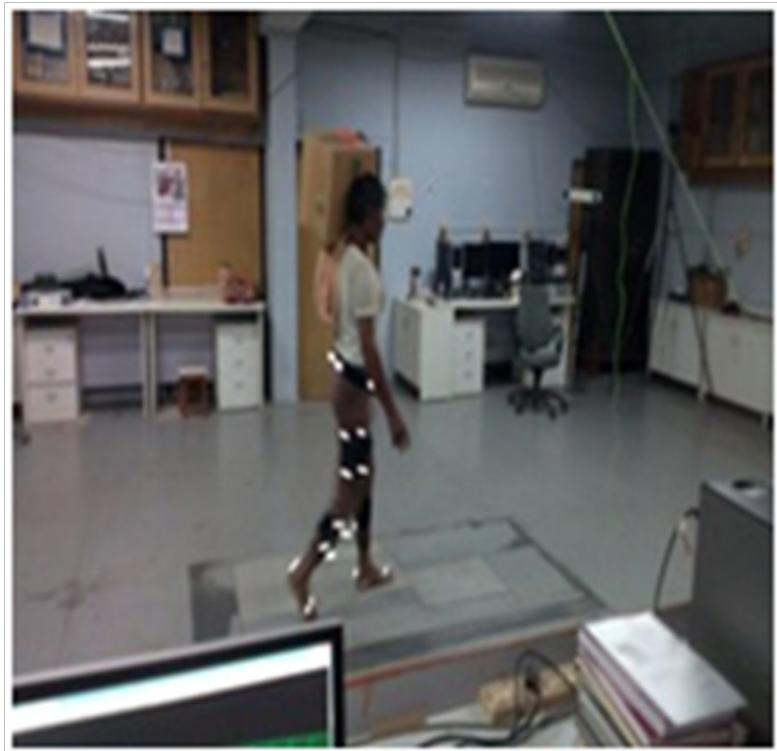

Figure C Shoulder Load (Subject's age- 39years).

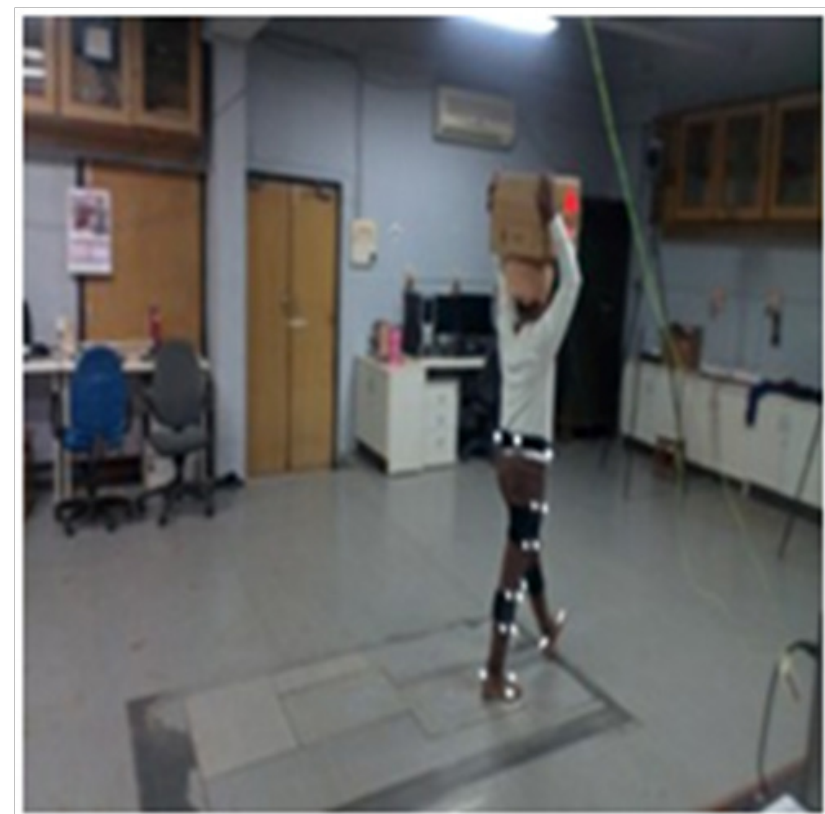

Figure B Head Load (Subject's age-30years).

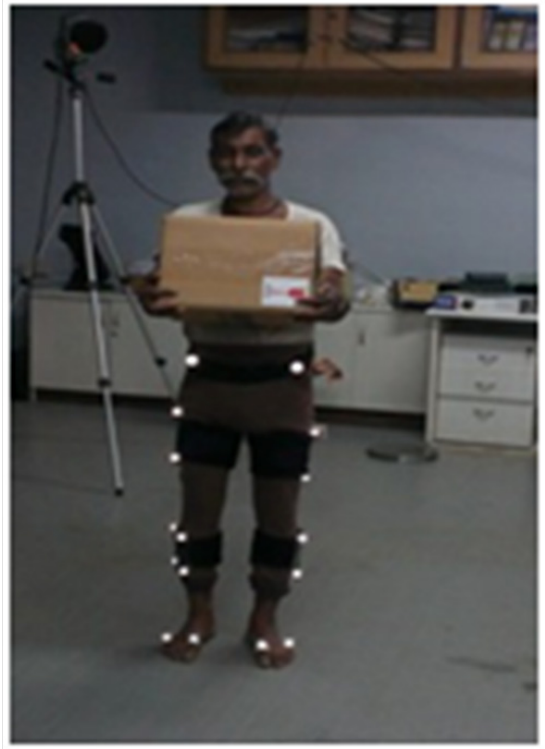

Figure D D. Hand Load (Subject's age-49years).

Figure I Different modes of load carriage with a load of 30kilogram carried by the construction workers of different age groups. 


\section{Data processing}

To record the walking activity of the workers the software 'Qualisys Track Manager' was used. The denotation of the tracking markers was also done in 'Track Manger'. To digitally reconstruct the subject's lower extremities anatomy, 'C-Motion Visual 3D' was used. This program was also used for the calculation of the gait parameters. Force plate data was also processed with 'Visual 3D'. To ensure that the cameras and force plates recording properly from both sides of the $y$-axis (defined as the direction of walking), the test subject entered the analyse-space from positive y-direction half of the trials, while the other half he was entering from the negative y-direction. To test the harmony between the plates, half the trails were done stepping with the subject's left foot on force plate-1. The second half of the trails the subject stepped with his right foot on force plate-2. Trials with discontinuities due to marker displacements were eliminated from the analysis. The best three trial out of five trials were considered for analysis. The data was analysed by visual 3D software (professional version). The gait report was generated for each worker and comparison was made. The selected trials were opened in Qualisys track manager and reconstruction was done to visualise the markers and labelling done appropriately by attaching plug in gait model to produce digital diagram. Heel strike of one foot followed by toe off and again heel strike of the same foot were marked manually in the gait cycle for each foot. The defined gait cycle and processed data of the three trials for each subject were saved and exported to excel files. This data was then processed further by the track manager software and used for creating models.

\section{Results and discussion}

The workers selected for the present study were between the age range of 21-40years performed the load carriage task and the ranges of their height and weight average height was 148.7-170.0 centimetres, and the weight was $43.5-68.9 \mathrm{~kg}$ The obtained mean age of the workers was $29.3 \pm 1.64$. Their mean height and weight were $165.5 \pm 7.42$ in centimetres and $59.5 \pm 8.6$ in kg respectively. The mean Body Mass Index (BMI) was 21.45 \pm 3.2 . The hip circumference and pelvis depth were measured to use as personal data input along with age, height and weight for the construction of the digital skeleton in the C-Motion Track Manager Software. All the demographic details of the workers were presented in Table 1. Age exhibited a positive correlation with all the gait parameters. Hip circumference and pelvis depth had a correlation with stride width. The correlations had been represented in Table 2.

Table I Demographic details of the construction workers

\begin{tabular}{lllllll}
\hline Variables & $\begin{array}{l}\text { Age } \\
\text { (years) }\end{array}$ & $\begin{array}{l}\text { Height } \\
(\mathbf{c m s})\end{array}$ & $\begin{array}{l}\text { Weight } \\
(\mathbf{k g})\end{array}$ & BMI & $\begin{array}{l}\text { Hip circumference } \\
\text { (cms) }\end{array}$ & $\begin{array}{l}\text { Pelvis depth } \\
(\mathbf{c m s})\end{array}$ \\
\hline Mean & 22.3 & 157.5 & 58.5 & 23.445 & 96.5 & 12.77 \\
$\begin{array}{l}\text { Standard } \\
\text { deviation }\end{array}$ & 1.636 & 7.424 & 8.647 & 3.195 & 6.1 & 1.8 \\
Range & $21-40$ & $148.7-170.0$ & $41.5-67.9$ & $17.61-27.65$ & $86-103.5$ & $10.3-16.5$ \\
\hline
\end{tabular}

BMI, body mass index; CM, centimetres; Kg, kilograms; M, meters; $S$, seconds; RL, right leg; LL, left leg

Table 2 Correlations of physical parameters with gait parameters

\begin{tabular}{lllllll}
\hline Variables & Speed & Stride length & Stride width & Double limb support & Cadence & Cycle time \\
\hline Age & -0.84 & 0.83 & -0.78 & 0.79 & -0.81 & 0.80 \\
Height & -0.32 & 0.52 & -0.06 & 0.09 & -0.12 & 0.45 \\
Weight & -0.48 & 0.20 & 0.30 & 0.28 & 0.12 & 0.33 \\
Hip Circumference & 0.32 & 0.45 & 0.91 & 0.55 & 0.21 & 0.36 \\
Pelvic Depth & 0.06 & 0.56 & 0.89 & 0.64 & 0.32 & 0.40 \\
\hline
\end{tabular}

The kinematic gait parameters such as stride length, cadence, cycle time and walking velocity showed significant difference on three different load carrying conditions. Stride length, stride width and walking speed showed significant difference on all the three methods. The mean gait parameters of the workers while carrying load in three different modes of load carriage were presented in Table 3. The changes in the gait parameters during each of the three modes of load carriage were compared by Student's t-test at a significant level of $p<0.05$. It was found that the deviation of stride length was minimum while carrying load on head whereas maximum was found on carrying load in hand. Maximum step time was taken during hand mode of load carriage whereas the minimum time was taken during head mode of load carriage. The stride width maintained during hand load followed by shoulder load were more wide compared to head load. The steps per minute (cadence) were more during hand load followed by shoulder load when compared to head load. The average number of strides taken by the workers were found to be minimum during head load and maximum number of strides were taken during hand mode of load carriage.

The swing time were found to decrease while carrying load. It was found to be least during hand load showing that workers were more prone to take the double limb support to maintain their stability. An optimal load-carrying configuration should allow a person to walk with less deviation from the normal leg movements with the least of amount of effort and discomfort. Guha Thakurta et al. ${ }^{6}$ in their study observed similar results while performing the study on Indian women and found head load to be more strategically correct considering minimum gait deviation. Significant differences in all the gait parameters were observed when the three modes of load carriage were compared at $\mathrm{p}<0.05$. The study done by Woo et al. ${ }^{7}$ also examined the effect of carrying method and weight on the 
walking patterns of subjects and demonstrated that subjects displayed significantly different gait patterns under experimental conditions. Gait parameters like stride length, cadence, cycle time, speed and etc. were all deviated by carried load. Results from the analysis of the present study revealed that heavy loads substantially modified the normal gait pattern. Similar observations were obtained from the study done by Kinoshita. ${ }^{8}$ Considering the physiological cost as well Soul \& Goldman ${ }^{9}$ in their study also found head loading to be more beneficial.

Table 3 Changes in gait parameters of the construction workers with three different modes of load carriage

\begin{tabular}{|c|c|c|c|c|c|c|c|c|c|}
\hline $\begin{array}{l}\text { Load } \\
\text { pattern }\end{array}$ & $\begin{array}{l}\text { Speed } \\
(\mathrm{m} / \mathrm{s})\end{array}$ & $\begin{array}{l}\text { Stride } \\
\text { length(m) }\end{array}$ & $\begin{array}{l}\text { Stride } \\
\text { width(m) }\end{array}$ & $\begin{array}{l}\text { Step } \\
\text { time(s) }\end{array}$ & $\begin{array}{l}\text { Stance } \\
\text { time (s) }\end{array}$ & $\begin{array}{l}\text { Swing } \\
\text { time (s) }\end{array}$ & $\begin{array}{l}\text { Double limb } \\
\text { support(s ) }\end{array}$ & $\begin{array}{l}\text { Cycle time } \\
\text { (s) }\end{array}$ & $\begin{array}{l}\text { Cadence-steps } \\
\text { per minute(s) }\end{array}$ \\
\hline Free Walk & $4.8 \pm 0.56$ & $1.03 \pm 0.01$ & $0.37 \pm 0.09$ & $0.40 \pm 0.13$ & $0.52 \pm 0.31$ & $0.46 \pm 0.16$ & $0.60 \pm 0.04$ & $1.02 \pm 0.19$ & $107.66 \pm 0.13$ \\
\hline Head Load & $4.0 \pm 0.11$ & $1.12 \pm 0.01$ & $0.4 I \pm 0.09$ & $0.46 \pm 0.09$ & $0.58 \pm 0.12$ & $0.5 I \pm 0.09$ & $0.65 \pm 0.19$ & $1.91 \pm 0.19$ & I $14.97 \pm 0.22$ \\
\hline Hand Load & $3.09 \pm 0.23$ & $1.19 \pm 0.04$ & $0.6 I \pm 0.05$ & $0.60 \pm 0.14$ & $0.69 \pm 0.16$ & $0.40 \pm 0.34$ & $0.91 \pm 0.06$ & $2.39 \pm 0.31$ & || $8.66 \pm 0.4 \mid$ \\
\hline $\begin{array}{l}\text { Shoulder } \\
\text { Load }\end{array}$ & $3.4 \pm 0.10$ & I. $14 \pm 0.06$ & $0.62 \pm 0.14$ & $0.53 \pm 0.13$ & $0.64 \pm 0.18$ & $0.43 \pm 0.13$ & $0.7 I \pm 0.05$ & $1.35 \pm 0.05$ & || $8.5 \mid \pm 0.16$ \\
\hline
\end{tabular}

$\mathrm{p}<0.05$

\section{Conclusion}

This study examined the effect of three modes of load carrying method on the walking patterns of the construction workers. The results of the study demonstrated that workers displayed significantly different gait patterns under experimental conditions. Gait parameters such as stride length, cadence, cycle time, stride width, double limb support and walking speed were affected by carried load. Carrying methods had an effect on all the gait parameters. Based on the results of this study, it is needed to consider gait parameters to understand the workload on carrying tasks. Workers could not sustain large stride length, normal walking speed because of load that was placed in the front in the hands of the workers. Such load placement restricted walking of the construction workers in India. The study revealed that comparing the three modes of load carriage the gait deviation were found to be less during head mode of load carriage compared to the hand mode and shoulder mode of load carriage among the Indian construction workers. The present study indicated that head loading has certain important advantages over hand loading and shoulder loading considering the effect on workers gait. Most particularly it is possible to carry greater loads on the head for longer duration and it is generally considered to be more comfortable for the manual Indian construction workers. Head loading is sometimes characterized by neck pain but long term habituation seemed to provide comfortable approach to the workers by maintaining less deviation from their normal gait. It is suggested that there is a need for further research into detail impact of load carriage on lower limb biomechanics in context with Indian construction industries.

\section{Acknowledgements}

Sincere thanks to the construction workers of Mumbai who volunteered for the present study for their constant cooperation. I would also like to express my heartfelt gratitude to my institute, National Institute of Industrial Engineering, for providing me with the necessary infrastructural support for carrying out my experiment.

\section{Conflict of interest}

The authors of the present study had participated sufficiently in the work to take the required responsibility for the whole content of the research paper, including participation in the idea, concept evaluation, analysis, writing, and revision of the research paper. Furthermore, each author of the research paper certifies the originality of the research work and also that this research material has not been and will not be submitted to or published in any other journal or with any other publishers.

\section{References}

1. Parida R, Ray PK. Factors influencing construction ergonomic performance in India. Procedia Manufacturing. 2015;3:6587-6592.

2. Jaiswal N, Veerkumar V. Work related musculoskeletal disorders among construction workers of India. Res J Family Community and Consumer Sci. 2016;4(2):1-5.

3. Hengel KMO, Blatter BM, Geuskens GA, et al. Factors associated with the ability and willingness to continue working until the age of 65 in construction workers. Int Arch Occup Environ Health. 2012;85(7):783-790.

4. Gallagher S. Physical limitations and musculoskeletal complaints associated with work in unusual or restricted postures: a literature review. J Safety Res. 2005;36(1):51-61.

5. Boschman JS, van der Molen HF, Sluiter JK, et al. Musculoskeletal disorders among construction workers: a one-year follow-up study. BMC Musculoskelet Disord. 2012;13(1):196.

6. GuhaThakurta A, Iqbal R, De A. The influence of load carrying modes on gait variables of healthy indian women. Ergonomics for Rural Development. 2015:443-447.

7. Woo DP, Lee SD, Lee DC, et al. Effects of carrying method and weight on gait parameters during load carrying tasks. Human engineering. 2002;38:62-64.

8. Kinoshita H. Effects of different loads and carrying systems on selected biomechanical parameters describing walking gait. Ergonomics. 1985;28(9):1347-1362.

9. Soule RG, Goldman RF. Energy cost of loads carried on the head, hands, or feet. J Appl Physiol. 1969;27(5):687-690. 